\title{
RURAL AREA POPULATION HEALTH WARE AS KEY FACTOR OF SERBIAN VILLAGE DEVELOPMENT
}

\author{
Emina Kričković*1, Milica Živanović*, Zoran Kričković** \\ * University of Belgrade - Faculty of Geography, Belgrade \\ ${ }^{* *}$ Military Geographical Institute - Ministry of Defence of the Republic of Serbia, \\ Belgrade
}

\begin{abstract}
Health of the rural area population depends on many environment conditions. Researches on health allows us to determine differences between population health and its needs and to identify potential risks of rural area. There are many factors affecting both individual and commune health of the living area. Therefore, the subject of this article are the factors affecting rural population health and they will be defined. These factors consider income, social relations, access and usage of fundamental communal services, such as water pipeline, sewage system, the quality of available health services, personal responsibility and environment.
\end{abstract}

Keywords: rural area, rural areas factors, villages, health, diseases, villages of Serbia.

\section{Introduction}

It is impossible to define precisely what health is for each community, because it depends on the perceptions of community members as to whether their village is a decent place to live. First and foremost a village or rural community can be considered healthy when rates of infectious diseases are low, when community members have access to basic services and health care needed for them, and when the community lives in a state of reasonable harmony.

1 Corresponding author: E. Kričković, University of Belgrade - Faculty of Geography, Studentski trg 3/III, Belgrade; e-mail: memina1989mail.com 
According to the World Health Organization (WHO) good health is not merely the absence of disease; it is also a reflection of the social and mental wellbeing of people in a community. Thus, to achieve the WHO goal of providing health for all, improvements in a community should aim not simply to reduce disease, but also to reduce social tensions and mental ill-health to acceptable levels. Public care regarding rural community health directed to lower the risk of diseases emerging and promote social well-being of people must consider many social factors and factors that affect the environment.

\section{Research methodology}

Main purpose of this article is evaluation and application of present scientific knowledge in the area of geosciences which will be conducted on the level of scientific description and data merging on environment and rural area population. Systematic research on impact of rural area factors affecting population is guided to research problem aimed to find adequate measures in protecting population of rural area.

The research problem in this article is population health in rural areas. There are many factors affecting both individual and community health. Therefore, the subject of this research are factors affecting population health in the rural area and they will be defined later in this article.

The aim of this article is to point the necessity of preservation of population health in rural areas of Serbia. Social aim of this research should provide scientific knowledge related to rural areas factors on population health in rural areas of Serbia as well as, based on these findings, undertake certain measures in clearing negative impact on human health and indirectly affect on the level of developed ecological awareness of both individual and community.

Basic hypothesis of this research derives from the fact that rural areas factors affect population health in these areas. In this article following research methods are used: analysis-synthesis, statistical method, geographic-ecological method, method of medical-geographical description, method of medical-geographic forecast as well as cartographic method.

The research - Rural Area Population Health Ware as Key Factor of Serbian Village Development should contribute professionally, scientifically and socially. Scientifically, it will present develop and application of theoretic-methodologically approach on the impact of rural areas on the population health. Professionally, it will present the possibility of personnel training for similar researches. Socially, it will point directions in order to reduce the affect of rural areas factors on population health. 


\section{Results and discussion}

Rural area factors that affect human health are different for importance in various communities, variety of available community services, objects, priorities in communities and their current needs and for that communities are changed and developed over time. According to the World Health Organization guide "Healthy Villages" (p. 7) factors that affect human health in rural area are:

- The environment;

- Individuals and communities' health awareness (creating a community questionnaire and participatory approaches could get the information);

- Personal hygiene;

- Health care;

- Diseases;

- Interpersonal relations and

- Rural community members' income.

To establish factor impact on the human health in rural area it is necessary to:

- Identify health problems and establish priorities,

- Identify causes of health problems and

- Use the information.

Some of the factors that affect human health in rural area will be presented in this paper.

\section{Water and human health in rural areas}

According to the WHO guide (p. 19) in order to reduce health risks emerged from water it is necessary to:

- Provide access to fresh water to the local community;

- Define types of water source (protected springs, dug wells, boreholes);

- Water pipeline;

- Rainwater harvesting

- Ponds, lakes and water treatment;

- Household water treatment (boiling, filters, disinfection and settling);

- Safe handling of water;

- Monitoring water quality (microbial quality, sanitary inspection and physicochemical quality), 
- Managing community water resources (preventing over-pumping of groundwater, water conservation as well as managing water for agriculture.

Numerous rural areas don't have water conducted to their homes, but people use water from wells, which reduces hygiene quality. Also, it is needed constant and continuous water quality monitoring, by which should be tested for presence of bacteria and harmful chemically substances in drinking water. This kind of monitoring of drinking water, technical water and water needed for agriculture use is precondition for preserving human health in rural areas. It is needed to pay a special care to water used for agriculture, due to inevitable consequences of using contaminated water.

Today, lack of water could present one of the biggest risks for human health in rural areas. In long term, society can survive only by using renewable resources. When the resource is not renewable, it can be available only certain period of time and when it is depleted faster than it can be renewed, supplies of this resource couldn't settle basic needs.

By itself, water is complex system. Ford (2005) in his paper "Water and health" (p. 454) considered that water can be polluted either by chemicals or by microbes, and those two class pollutants affect to each other. Some chemicals are toxins originated from bacteria, fungi or algae. In spite of risk, people in the area with contaminated water could be, in contrary, protected by immune system due to long-term exposure to the same pathogen. This kind developed immune system must have certain cost to individual, but there are not clear approaches to disease affect due to exposure of greater polluted agents and toxins. This complexity as well as complexity of water continues to challenge the assessment of microbial risks. Increased host adaptability could be responsible for greater number of infections in population which previously was not exposed to infections.

As exposure to chemicals, so the exposure to water pathogens could originate from different sources. The mechanism of disease spreading through water considers importation of microorganisms by drinking water as well as through skin contact with contaminated water.

The prime source of information regarding impact of water diseases on human health is WHO. Every year WHO publishes World health report with numerous annexes describing mortality and the number of people infected with certain disease. Data presented in this report are for previous year and are gathered from national health databases, it is estimated that presents 30 percent of all diseases in the world. One of the basics of the WHO in fighting contagious diseases is providing healthy potable water to people. 
Today, the efforts are made in removing all the dangers threaten individuals and communities, due to possibility of spreading contagious diseases through water usage. By Krajinovic and Radovanovic (1985) these dangers are in so called unhygienic water objects. These objects sometimes could be very big, so the big number of people is affected.

As the WHO is primary source of information on water diseases in the world, that is the Institute for public health of Serbia "Dr Milan Jovanovic Batut" in Serbia. Every year the Institute publishes Health-statistics yearbook of the Republic of Serbia for previous year, where population health is presented. According to report for 2017 (p. 489) five counties out of 24 (excluding Kosovo and Metohija and city of Belgrade) didn't have correct public water supply and those were: Severnobacki, Zapadnobacki, Severnobanatski, Srednjebanatski and Pirot. These public water suppliers did not meet standards for physicochemical quality, microbiological safety or both.

It is noticeable that four out of five public county water suppliers with irregular water quality are in Vojvodina province, with overall seven Vojvodina's counties. This data is easy to compare with data from the SEPA Report on Environment in Serbia for 2013 where it is established that the lowest quality for period from 1983 to 2013 are the waters of Vojvodina's canals and rivers. Expressed by Serbian Water Quality Index in category "very bad quality", 79\% out of all samples controlled are from Vojvodina province. In the same Report (p. 46), pour state of Vojvodina's water quality is also confirmed by data from same report where it is stated that $59 \%$ of water samples are in category "bad" and "very bad". In the Report for 2017 (p. 40) according to BPK-5² indicator water quality in Serbia's watercourses is deteriorating in period from 2013 to 2016, and decreasing trend of BPK-5 indicator is determined in Danube basin in period from 2007 to 2016. Unfavourable water quality is noticed in three locations in Vojvodina province.

According to the SEPA Report for 2017 (p. 44), indicator showing contents of ammonium $\left(\mathrm{NH}_{4}-\mathrm{N}\right)$ water quality of Serbian watercourses is constantly deteriorating in period from 2007 to 2016. This indicator follows the concentration of ammonium in rivers and provides insight in state of surface water in state of ammonium. It is used for presenting spatial and time variation of substances which use oxygen and their long-term trend. Ammonium is indicator of possible bacterial activity of human and animal waste which through sewage system or by rinsing comes to surface water.

2 This indicator follows concentration of oxygen biologic spending in rivers and provides insight in state of surface water in the sense of biodegradable organic load. It is used to show spatial and time variation of substances which use oxygen and their long-term trend. The concentration of oxygen biologic spending is prime indicator of polluted surface water by organic substances. 
According to the same report nitrates in Serbia's rivers have very low concentration. This indicator follows the nitrate concentration $\left(\mathrm{NO}_{3}-\mathrm{N}\right)$ in rivers and provides insight of surface water in term of nutrient concentration. It is used to express spatial and time variation of nutrients and their long-term trends. The most significant source of nutrient pollution is rinsing from farmlands. According to this indicator, the water quality in Serbia's watercourses is constantly improving in period from 2007 to 2014 with slight deterioration in period from 2014 to 2016.

It is understandable that the most important consideration of protection human health in the sense of availability of fresh potable water, consider preserving fresh water sources. It is necessary to estimate potential risks of water pollution in rural areas as well as procedures in case of emerging water-borne diseases. Considering data from these reports it is easy to conclude that the most polluted water is in Vojvodina province, the trend is in increased pollution through human and animal waste but there is also pollution decrease regarding pollutant from agriculture, which is very positive for villages' development.

\section{Human waste and excreta management}

There are various sewage systems, from primitive to high technological. Usually, there are not existing public sewage systems in rural areas, but sanitation water is drain away to septic tanks, which are made for every household individually. Septic tanks are not built by plans, so it is possible to soil become contaminated through underground water. During septic tank construction it is needed to pay attention to its location and adequate manage it, so there would be not consequences for human health. Unhygienic situation could lead to polluted soil and drinking water and spread causes of contagious diseases. Due to this fact in rural areas intestinal infections are more common, and due to close contact with nature and domestic animals, vector-borne diseases and anthroponosis are also more common.

Human was always aware that human and animal waste could pollute water and jeopardise human health. Many pathogen organisms could be found in water. Biological pollutants could emerge from spotted and non-spotted sources as chemical pollutant. Because the majority of chemical pollutant (but not all) emerge from human or animal waste, managing wastewater in rural area plays a major role in health protection.

In rural areas special attention should be conducted during construction of pit latrine, as its construction is inevitable. It is essential to pay attention during maintaining and usage of this kind of toilets as well as in way of managing excreta, in order to prevent environmental and human health contamination. 
Excreta managing and human waste disposal is needed to pay greater attention in rural areas, because if it is inadequate managed the negative effects on human health are inevitable. This is possible through appropriate technologies for excreta disposal and sewage management, as well as its usage. According to the WHO guide (p. 39) technologies for excreta disposal are:

- Daily disposed waste;

- Pit latrine (without flush or pour-flush latrines in areas with Muslims majority);

- Septic tanks and

- Sewage systems.

Sewage system management could be conducted also through wastewater stabilisation ponds and sludge reuse. In Serbia, data regarding percentage of population connected on public sewage system is provided by Statistical Office of the Republic of Serbia. As the biggest sewage system in Serbia is Belgrade sewage system. It is reflection of whole social development in Serbia. Nedeljkovic, N., et al. (2017), p. 27, stated that entire system is characterised by wastewater and surface water in Danube and Sava rivers and other city watercourses without any purification.

According to SEPA report on environment in Serbia for 2017 (p. 59) the number of inhabitants connected to public sewage systems is in constant rise and counts $61.3 \%$ in 2016, and the percentage of Serbian population included in wastewater treatment is $13.99 \%$, and only $3.46 \%$ is included in tertiary treatment, as the most perfect treatment for purification of wastewater. Approximately $40 \%$ of population use septic tanks for excreta disposal, while $7 \%$ using dry systems and inadequate installations for excreta disposal. It is evident difference in numbers of population included in public sewage systems and public water suppliers, which presents very big danger for contamination of underground water. Figure 1 shows percentage of population included in public sewage systems through areas.

\section{Drainage}

Removing storm water and household wastewater is an important environmental health intervention for reducing disease. In areas where drainage and sanitation are poor, water runs over the ground during rainstorms, picks up faeces and contaminates water sources. This contributes significantly to the spread of diseases such as typhoid and cholera, and may increase the likelihood of contracting worm infections from soil contaminated by faeces. Flooding, on the other hand, may displace populations and lead to further health problems. 


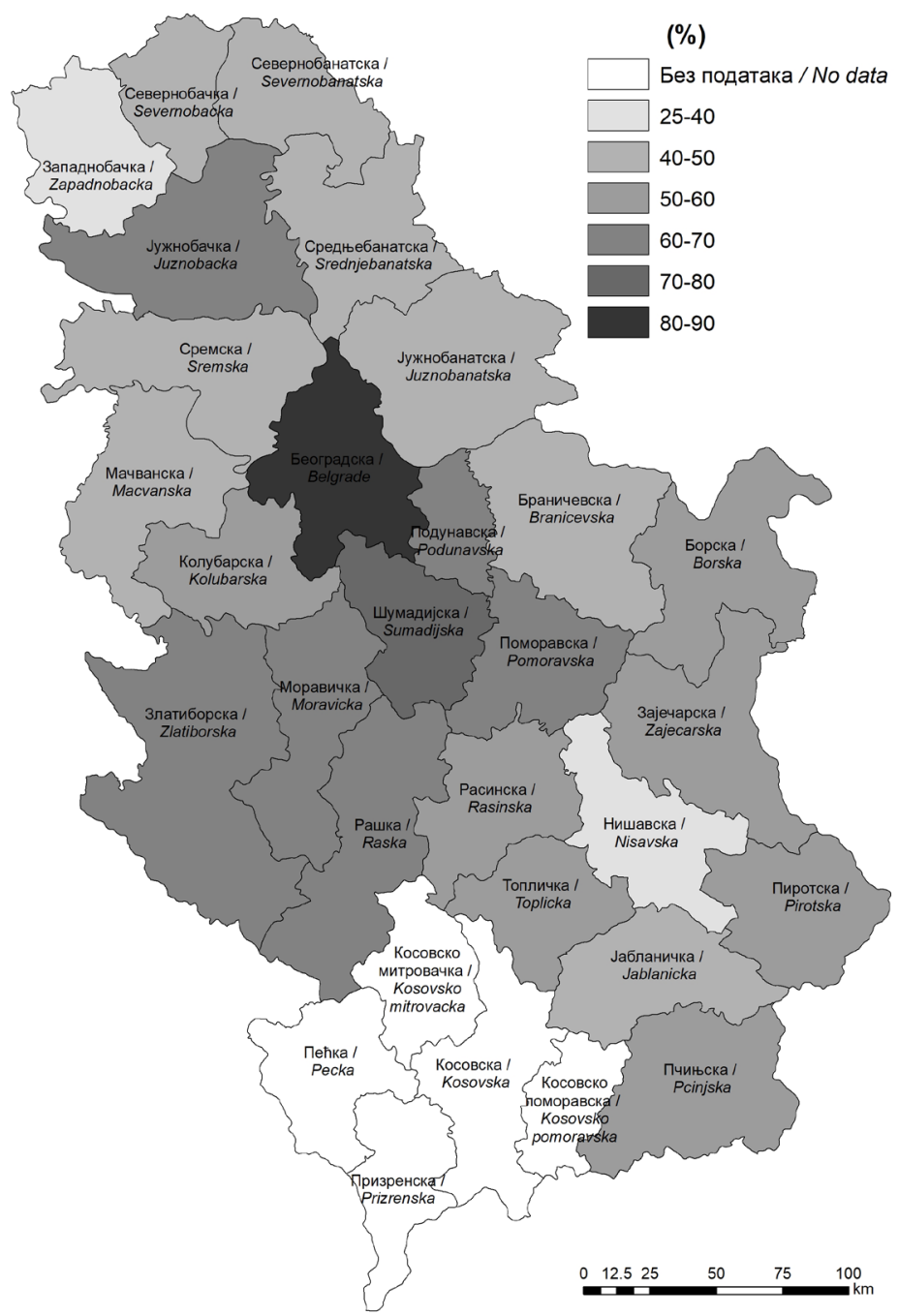

Figure 1. Percentage of population included in public sewage systems by areas (Source: SEPA Report on Environment in Serbia for 2017 (p. 60), figure is edited)

According to the WHO guide (p. 49) methods for improving drainage are:

- Storm water drains;

- Sullage disposal methods (containing little or no detergent);

- Combined drains and

- buried drains and combined sewers. 


\section{Solid waste management and chemical safety}

Community services and community hygiene are important for environment in rural area, because without preserved environment there is not quality life for individuals. The environment quality in some rural area community is directly or indirectly reflected on human health. Diseases with cause-and-effect relation to environment are numerous and should prevent it. Special attention should be paid to waste management system in rural areas. System of waste collection and waste management system in some rural area is very important for the environment and human health. There is not organised solid waste collection in lots of rural areas and individuals take their garbage to forbidden locations, where odour is spread, rodents and other animals are attracted and environment is polluted.

It is necessary to develop organised solid waste collection in all rural areas. Each household should have certain baskets for garbage collection, and they would be taken to suitable location where the solid waste could be recycled in accordance with all regulations. The existence and proximity of sanitary landfill, recycling centre or centre for waste burning and biogas production is of big essence for development of any rural area.

In rural areas special attention should be paid to certain categories of waste. It is necessary to manage special kinds of waste in accordance with all EU regulations and recommendations. Also, if some toxic substance is used it is necessary to adequate manage it and handling with it. Out of most importance is to take special attention to disposing of the toxic substances and prevent possible contact with human solid waste.

According to the WHO guide (p. 52) in order to prevent negative effects on human health through solid waste and toxic substances it is necessary to:

- Define Strategies for solid waste management (minimizing waste and recycling);

- Managing solid waste in households (possibility of composting as well as turning organic waste into fuel);

- Managing solid waste in the community (possibility of construction of communal refuse pit which is possible to reuse as well as local waste collection);

- Managing special solid wastes (health care solid wastes, slaughterhouse solid wastes and industrial solid wastes),

- Conduct process of chemical safety (storage, handling and disposal of toxic chemicals which are used in households and rural areas). 


\section{Household quality}

Household quality is important factor in determination of human health in rural areas. According to the WHO guide (p. 61) impact factors on health risk on human health are:

- Ventilation/heating;

- Lighting;

- Vector diseases in home as well as

- Overcrowding in homes.

Household quality has great impact on human health and therefor on rural areas development. If population in rural areas has "quality" household and proper conditions for working and living it is inevitable for villages to develop and improve. Relief exposition is important regarding homes locations. North exposition is unfavourable for homes locations due to insufficient lighting. Every room in home should have sufficient lighting, because the lack of lighting can cause negative effects on human health. Insufficient lighting causes emerging mould, fungi and bacteria and it has a negative effect on complete human nerve system.

It is very needed to pay a special attention to ventilation and type of fuel used for heating, which is in our rural areas distinct problem. It is essentially to decrease harmful sources of energy and promote ecologically renewable sources of energy continuously.

Overcrowding homes is factor which has negative effect on human health, so it is needed to monitor on "home capacity". Big number of people in small space has numerous negative effects on human health, especially on complete nerve system, causing anxiety as well as sleep disorder. Excessive number in population density reduces comfort and leads to overcrowding and increased number of contacts which epidemiologically are not harmless.

Ljesevic and Milincic (2011) stated that Ecologist from the USA consider that in conditions of high standards for one man is needed 2 ha of territory (this include 0.2 ha for housing and industrial needs, 0.6 for food production, while the rest of 1.2 ha must stay intact for rest, recreation, travelling etc.). By the American researchers this is psychological standard which is necessary to individual for spatial activity, strengthen which provides sufficient psychological comfort.

\section{Personal and community hygiene}

Hygiene is essential for human health in rural areas. Methods for managing with agricultural crops and animals is primary precondition for preserving human health. 
According to the WHO guide (p. 55) people in rural areas should conduct next procedures and processes, which are in accord with basic hygiene normative:

- Personal hygiene (hand washing, bathing, laundering);

- Community hygiene (markets, animal rearing);

- Food hygiene (food preparation in the home, eating-houses, street foodvendors etc. which are in accord with sanitary-hygienic principles as well as promoting nutrition).

According to the WHO guide (p. 74) in order to emphasize the importance of hygiene in population in rural areas it is necessary to conduct following procedures:

- Assessing hygiene practices;

- Planning hygiene promotion projects;

- Implementing hygiene promotion projects:

- Building community capacity;

- Organizing groups and committees;

- Current situation analysis;

- Communication and education;

- Monitoring and evaluating hygiene projects:

- Deciding what information is needed;

- Selecting project investigators;

- Selecting tools for collecting information;

- Reviewing project findings,

- Feedback and dissemination of findings.

Institute of Public Health of Serbia "Dr Milan Jovanovic Batut" also conducts analysis and controlling of hygienic habits of Serbian population. In Health Statistical Yearbook of Republic of Serbia for 2017 (p. 532) is stated that in 2013 progress in hygiene habits was made. However, the percentage of population washing hands regularly decreased in compare with 2006 - from $73.8 \%$ to $64.7 \%$. Table 1 clearly shows differences of hygienic habits of city and rural area population in Serbia. 
Table 1. Hygienic habits of population in Republic of Serbia according to settlement type, gender, age, education and income in 2013

\begin{tabular}{|c|c|c|c|c|}
\hline \multirow{2}{*}{\multicolumn{2}{|c|}{$\begin{array}{l}\text { Geographic, demographic and } \\
\text { social-economic characteristics }\end{array}$}} & $\begin{array}{l}\text { Regular hand } \\
\text { washing }\end{array}$ & $\begin{array}{c}\text { Regular } \\
\text { brush teeth }\end{array}$ & $\begin{array}{l}\text { Regular bathing/ } \\
\text { showering }\end{array}$ \\
\hline & & $\%$ & $\%$ & $\%$ \\
\hline \multirow{2}{*}{$\begin{array}{l}\text { Settlement } \\
\text { type }\end{array}$} & City & 67,4 & 58,8 & 73,8 \\
\hline & Other & 60,7 & 41,1 & 59,7 \\
\hline \multirow{2}{*}{ Gender } & Female & 71,8 & 60,4 & 72,3 \\
\hline & Male & 57,0 & 42,3 & 63,5 \\
\hline \multirow{8}{*}{ Age } & $15-24$ & 63,8 & 71,9 & 86,5 \\
\hline & $25-34$ & 68,8 & 66,5 & 88,3 \\
\hline & $35-44$ & 69,7 & 57,7 & 81,5 \\
\hline & $45-54$ & 65,4 & 47,6 & 71,7 \\
\hline & $55-64$ & 62,5 & 41,5 & 58,8 \\
\hline & $65-74$ & 63,1 & 36,9 & 43,3 \\
\hline & $75-84$ & 56,6 & 25,4 & 24,7 \\
\hline & $85+$ & 45,0 & 24,6 & 16,4 \\
\hline \multirow{3}{*}{ Education } & Elementary and lower & 58,50 & 37,00 & 50,74 \\
\hline & High school & 65,68 & 53,49 & 74,33 \\
\hline & University and higher & 72,08 & 69,85 & 77,68 \\
\hline \multirow{5}{*}{ Income } & Poorest & 57,7 & 31,5 & 47,8 \\
\hline & Poorer & 62,7 & 43,8 & 63,5 \\
\hline & Middle class & 64,1 & 52,5 & 69,7 \\
\hline & Richer & 70,3 & 60,8 & 77,1 \\
\hline & Richest & 68,9 & 69,8 & 83,4 \\
\hline \multicolumn{2}{|r|}{ Serbia } & 64,7 & 51,7 & 68,1 \\
\hline
\end{tabular}

Source: Health Statistical Yearbook of Republic of Serbia for 2017, p. 532

\section{Providing health care}

According to the WHO guide (p. 82) for providing adequate health care in rural areas following procedures are necessary:

- Organising primary health care facilities;

- Establishing community health care programmes;

- Defining factors that influence the type of health care that people seek; 
- Encouraging and sustaining the use of health services;

- Immunization of children (overcoming barriers to immunization and making immunization safe);

- Groups with special health care needs (pregnant women, infants and the elderly);

- Defining Risky behaviour and prevention measures (changing risky behaviour and health education);

- Develop strategies for individuals with mental health problems, learning difficulties and epilepsy (record and determine mental health problems, learning difficulties, epilepsy as well as social inclusion).

Health care is very important for rural areas. It is needed to have as much big number of physicians as possible who will be in charge for certain population number according to WHO standards (Serbia in 2017. - 2.463 physician on 1000 population, and in the world according to WHO $45 \%$ of state members has less than 1 physician per 1000 population) and EU (average in EU is 3.5, but in Serbia is 3.1 physician per 1000 population). According to Institute of Public Health of Serbia" dr Milan Jovanovic - Batut", by the end of 2017, in Serbia was 2.85 physicians per 1000 population, without dentists and pharmacists.

Availability and organisation of health care in rural area is very important for its development. Depending on the way primary health care facilities are organised depend the quality of health care of rural areas population.

The term "health care" is possible to determine in several ways. One of the most accepted definition points that the quality health care is the one providing organisation of health resources and capacities in the most efficient way, so the individuals' needs for prevention and treatment are provided in safe manner. It is important to understand that the quality is not made of quantity i.e. the number of provided resources, but out of way that the resources are used.

By Obradovic-Arsic and Gledovic (2012), in Serbia, health care facilities are organised in three levels (primary, secondary and tertiary). On the primary level are community-health centres (community-health centre branches, infirmary, and health stations) as well as pharmacy. On the secondary level are general and specialized hospitals and on the tertiary level are clinics, institutes, clinic centres, university hospital medical centre. Figure 2 shows the number of physicians per 100000 population by counties.

It is needed to raise the awareness of health prevention among rural areas population, as individuals in those areas, due to large distance from health care facilities, don't meet physicians and don't control their health. It is necessary to promote health prevention and health control in these areas. This is possible through organised physician's visits to rural areas population and vice versa. 


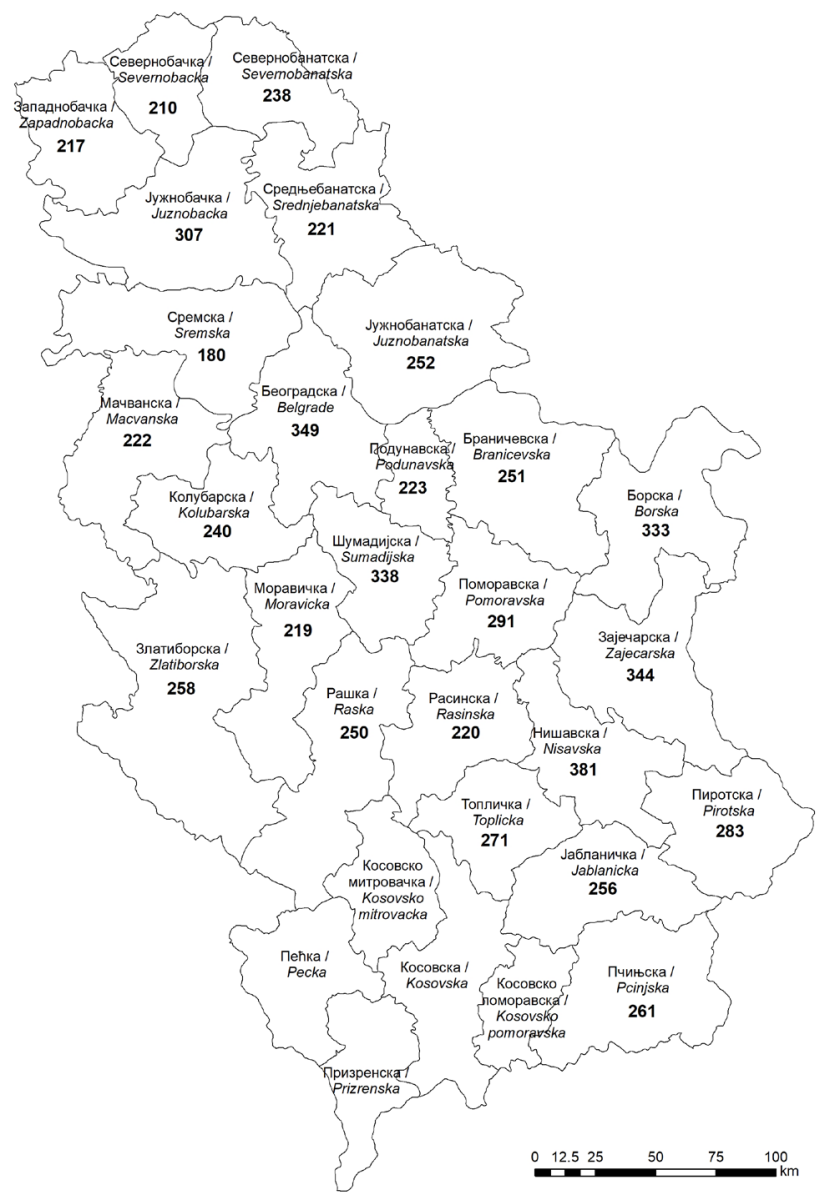

Figure 2. Number of physicians per 100000 population by counties (Source: Health Statistical Yearbook of Republic of Serbia for 2017 (p. 66), figure is edited)

\section{Conclusion}

There is no question if the factors of rural areas have impact on human health. Therefore, it is necessary to estimate health risks which derive from rural areas. The risk assessment in rural areas is very important because it represents the process which prioritises interventions and reduces human exposure to potentially harmful substances which may occur. Nevertheless, the risk assessment needs extra considerations which are referred to assessment of external influences, diversity and complexity. 
In the same way, there could be differences in immune system of individuals as well as quantity and types of harmful substances. People are also different by the body response on infective dose, depending on predisposition (age, general health conditions and other factors). It is necessary through defining prevention and protection measures for population to adequately manage health risk in rural areas. If some negative consequences arise or some epidemic or disease emerge it is necessary to apply suppression measures.

\section{Acknowledgements}

The paper is the result of the research within the project no. 176008 funded by the Ministry of Education, Science and Technological Development of the Republic of Serbia.

\section{Literature and data sources}

Obradovic-Arsic, D., Gledovic, Z. (2012). Medical Geography. Belgrade: University of Belgrade - Faculty of Geography.

Krajinovic, S., Radovanovic, Z. (1985). General Epidemiology. Belgrade: University of Belgrade - Faculty of Medicine.

Ljesevic, M., Milincic, M. (2011). Demoecology, Script for students of University of Belgrade - Faculty of Geography.

Ford, T. (2005). Water and Health, In: H. Frumkin (Ed.) Environmental Health: From Global to Local (pp. 413-450). San Francisco: John Wiley \& Sons - Jossey-Bass.

Health at a Glance: Europe 2016, State of Health in the EU Cycle. Joint publication of the OECD and the European Commission available on: http://www.oecd.org/ health/health-at-a-glance-europe-23056088.htm

Healthy Villages (2002). A guide for communities and community health workers. Guy Howard, Water, Engineering and Development Centre, Loughborough University, Loughborough, England. World Health Organization Geneva.

WHO records available on: http://www.who.int/gho/health_workforce/ physicians_density/en/

Nedeljković, N. et al. (2017). Banatski sewage system - improving public health and protection of water. Water and Sanitary Engineering, br. 3-4, pp. 27-34.

Agency for Environmental Protection (2014). SEPA Report on Environment in Serbia for 2013. Belgrade: Ministry of Agriculture and Environment of the Republic of Serbia. 
Agency for Environmental Protection (2018). SEPA Report on Environment in Serbia for 2017. Belgrade: Ministry of Agriculture and Environment of the Republic of Serbia.

Institute for public health of Serbia "Dr Milan Jovanovic Batut" (2018). Health Statistical Yearbook of Republic of Serbia for 2017. Belgrade: Institute for public health of Serbia "Dr Milan Jovanovic Batut". 